\title{
Development of Hierarchically Porous lonomer Membranes for Versatile and Fast Metal Ion Conduction
}

\section{Journal Article}

Author(s):

Hänsel, Christian; Kundu, Dipan

Publication date:

2019-02-28

Permanent link:

https://doi.org/10.3929/ethz-b-000325084

Rights / license:

In Copyright - Non-Commercial Use Permitted

Originally published in:

ACS Omega 4(2), https://doi.org/10.1021/acsomega.8b03552 


\title{
Development of Hierarchically Porous lonomer Membranes for Versatile and Fast Metal Ion Conduction
}

\author{
Christian Hänsel and Dipan Kundu**i) \\ Laboratory for Multifunctional Materials, Department of Materials, ETH Zurich, Vladimir-Prelog-Weg 5, 8093 Zurich, Switzerland
}

Supporting Information

\begin{abstract}
Innovative design concepts can play a key role in the realization of high-performance ionomer membranes that are capable of exclusive metal ion conduction and potentially applicable in electrochemical devices including sensors, fuel cells, and high-energy batteries. Herein, we report on the development of new ionomers, based on sulfonated poly(ether ether ketone) (SPEEK), engineered to conduct a variety of ions, namely, $\mathrm{Li}^{+}, \mathrm{Na}^{+}, \mathrm{K}^{+}, \mathrm{Zn}^{2+}$, and $\mathrm{Mg}^{2+}$, when soaked with nonaqueous solvents. Application of a facile phase-inversion method results in M-SPEEK $(\mathrm{M}=\mathrm{Li} / \mathrm{Na} / \mathrm{K} /$ $\mathrm{Zn} / \mathrm{Mg}$ ) membranes with a hierarchical porous network, facilitating organic solvent infusion that is necessary to

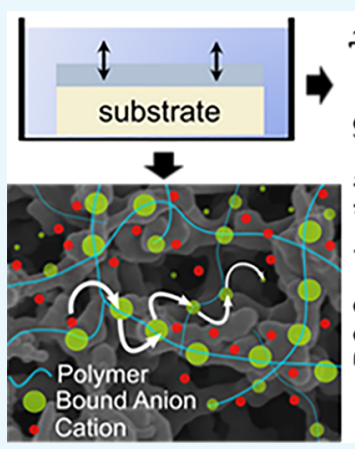

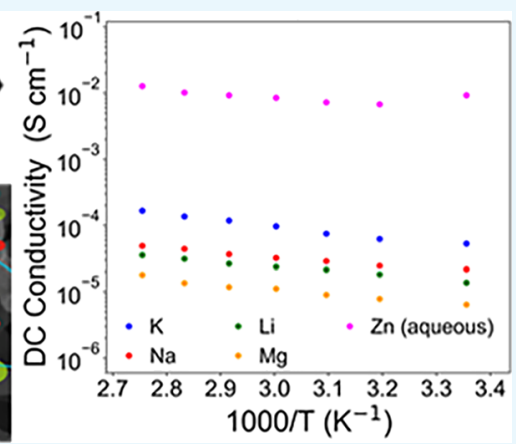
promote dissociation and rapid transport of cations between anionic sulfonate groups on the polymer chains. This strategy leads to membranes with alkali ion conductivities approaching $10^{-4} \mathrm{~S} \mathrm{~cm}^{-1}$ at room temperature, and near unity cation transference numbers $\left(t_{\mathrm{M}^{+}} \geq 0.9\right)$. Furthermore, an exceptionally high $\mathrm{Zn}$-ion conductivity of $10^{-2} \mathrm{~S} \mathrm{~cm}^{-1}$ is obtained for the water-infused $\mathrm{Zn}$-SPEEK membrane. In comparison, the dense membranes demonstrate 2-3 orders of magnitude lower conductivities because of insufficient solvent infusion. Preliminary electrochemical studies with solvent-infused ionomer membranes as the electrolyte look promising.
\end{abstract}

\section{INTRODUCTION}

Polymer electrolytes have enjoyed great deal of attention in the past 2 decades owing to their potential applications in electrochemical sensors, electrochromic displays, fuel cells, and high-energy batteries. ${ }^{1}$ Typically, they are metal saltpolymer complexes where both cations and anions are mobile. Because only one type of ion (cation/anion) participates in the electrochemical process, application of an electric field leads to the accumulation of inactive ions at the electrode-electrolyte interface. This results in polarization losses, which is detrimental to the performance of the electrochemical device. ${ }^{2}$ Polymeric single-ion conductors-also termed as ionomershave one of the ionic groups covalently tethered to the polymer backbone and thus eliminate the ionic concentration gradient build-up, resulting in electrolytes with near unity cation/anion transference number $\left(t_{+/-}\right)$. Such electrolytes have been proposed to improve the performance of metal ion batteries as exclusive metal ion conduction may not only increase the energy density ${ }^{3}$ but also stabilize metal deposition at the metallic electrode which is crucial to prevent dendrite formation. $^{4-7}$ Lithiated Nafion, a kind of perfluorinated sulfonate ionomer, is a prime example. ${ }^{8,9}$ It displays a $\mathrm{Li}^{+}$ transference number of $0.8-0.9$ and a high $\mathrm{Li}^{+}$conductivity nearing $10^{-4} \mathrm{~S} \mathrm{~cm}^{-1}$ at room temperature, when the Li-Nafion membrane is infused with liquid organic carbonates, such as propylene carbonate, ethylene carbonate, diethyl carbonate, or their mixtures. ${ }^{9}$ Notably, a variety of solid ionomers have been synthesized to date, but most of them display poor ionic conductivities $\left(10^{-6}\right.$ to $\left.10^{-8} \mathrm{~S} \mathrm{~cm}^{-1}\right)$ because of the lack of functional media that can promote $\mathrm{Li}^{+}$transport between the anionic groups. ${ }^{10}$ This issue has been addressed by functionalizing the polymer chain with flexible polymeric unit like PEO (poly ethylene oxide), ${ }^{11-13}$ which can act as a Lewis base and facilitate the movement of $\mathrm{Li}$ ions through the polymer matrix. In another strategy, the ionomer is blended with a PEO type soft polymer, which then functions as the $\mathrm{Li}^{+}$ transporter through Lewis acid-base interactions with $\mathrm{Li}$ ions. However, highest conductivity improvement has been documented for liquid organic solvent impregnation into the ionomer. The organic solvent simply assists in the solvationdesolvation-mediated transport of $\mathrm{Li}^{+}$- same way as the PEO type additive-without affecting the single-ion conductivity feature. ${ }^{9,14}$ Unfortunately, many ionomers do not imbibe liquid organic carbonates, the common solvents for binary Li-ion electrolytes, well. Therefore, they are functionalized with highly fluorinated functional groups-either in the backbone or in the anionic chain ${ }^{9}$ or blended with fluorinated polymers like polyvinylidene fluoride (PVDF), ${ }^{15}$ to improve their swelling behavior, which is crucial for high ionic conductivity. The issue concerning those approaches is that the fluoropol-

Received: December 18, 2018

Accepted: January 22, 2019

Published: February 5, 2019 


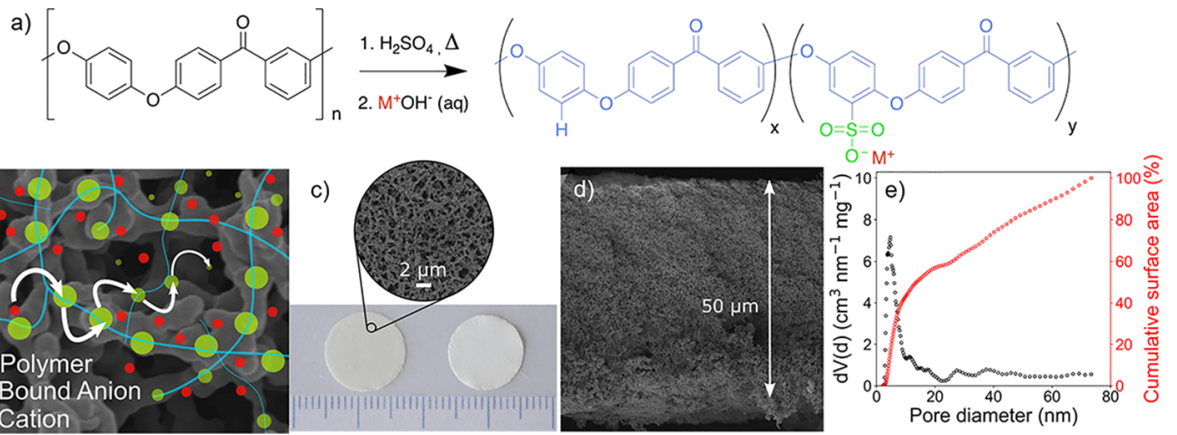

Figure 1. Development of porous M-SPEEK membranes. (a) Schematic of the M-SPEEK synthesis and (b) schematic illustration of the metal ion conduction in a porous ionomer membrane where the pores are filled with pure organic solvent. (c) Optical photographs of a dry (right) and a wet (left) (soaked in EC-DEC) Na-SPEEK membrane; the zoomed image is the SEM micrograph of the porous membrane surface. (d) SEM micrograph of the cross section of a $50 \mu \mathrm{m}$ thick porous Na-SPEEK membrane. (e) DFT pore-size analysis on the desorption branch of the BET isotherm for a porous Na-SPEEK membrane. All of the analyses shown here correspond to Na-SPEEK with DS $=63 \%$.

ymers can be expensive, and fluorination at the anionic chain involves complex synthetic strategies.

As we report here, hierarchically porous ionomer membranes of sulfonated poly(ether ether ketone) (SPEEK) designed by a facile phase inversion method offer a rigid network of interconnected nanopores. These interconnected pores efficiently infiltrate liquid organic solvents, which leads to good ionic conductivities with single-ion conductivity feature. SPEEK is known as an inexpensive alternative to Nafion in polymer electrolyte membrane (PEM) fuel cells as a proton conducting electrolyte. ${ }^{16,17}$ SPEEK has very good thermal stability, and it can be easily synthesized by sulfonation of poly(ether ether ketone) (PEEK). Upon exchanging the proton in the $\mathrm{SO}_{3} \mathrm{H}$ (sulfonic acid) group for different metal ions (Figure 1a), we have developed ionomer membranes capable of conducting $\mathrm{Li}^{+}, \mathrm{Na}^{+}, \mathrm{K}^{+}, \mathrm{Mg}^{2+}$, and $\mathrm{Zn}^{2+}$ when soaked with liquid organic carbonates. It is important to note that no salt is added to the organic carbonates that the membranes are infused with; therefore, only the metal ions from the polymer backbone contribute to the ionic conduction through the membranes. To the best of our knowledge, the development of versatile ionomer membranes from a simple polymer like SPEEK with potential for application as nonaqueous electrolytes is so far unprecedented. Remarkably, the interconnected porous network renders relatively large surface area of $\sim 35 \mathrm{~m}^{2} \mathrm{~g}^{-1}$, enabling solvent infusion, which is crucial to promote dissociation and transport of tethered cations (Figure 1b). The alkali ionomer membranes soaked in liquid organic carbonates register ionic conductivities nearing $10^{-4} \mathrm{~S} \mathrm{~cm}^{-1}$ at room temperature, besides asserting single-ion conductivity feature $\left(t_{\mathrm{M}^{+}} \geq 0.9\right)$. Solvent polarity is found to influence the ionic conductivity as exemplified by an impressive $10^{-2} \mathrm{~S} \mathrm{~cm}^{-1}$ zinc ion conductivity of $\mathrm{Zn}$-SPEEK membrane infused with water. Finally, preliminary electrochemical studies demonstrate reversible metal ion conduction through the ionomer membranes and manifest the possibility to use the Li-SPEEK ionomer electrolyte in $\mathrm{Li}$-ion batteries.

\section{RESULTS AND DISCUSSION}

Ionomer Membrane Preparation and Characterization. PEEK can be readily functionalized to SPEEK via an aromatic sulfonation reaction. ${ }^{18}$ Because the sulfonate groups $\left(-\mathrm{SO}_{3}{ }^{-}\right)$in SPEEK binds covalently to the polymer backbone, it becomes immobilized in space, but the counter cation $\left(\mathrm{H}^{+}\right)$ can move freely. Thus, hydrated SPEEK serves as a fast proton conductor in PEM fuel cells. The proton of the $-\mathrm{SO}_{3} \mathrm{H}$ group can in principle be exchanged with various metal cations, resulting in different single-ion conductors (Figure 1a).

The number of sulfonated repeat units in SPEEK can be readily adjusted by varying the reaction time and temperature (Table S1). In general, a higher reaction temperature and a longer reaction time result in higher number of sulfonated repeat units, expressed as the degree of sulfonation (DS). It is known that SPEEK with a high DS swells heavily in water. A larger counter cation $\left(\mathrm{Na}^{+}\right)$interacts less with water than the proton and consequently SPEEK with a larger counter cation swells less in water. To simplify the washing and further processing, as-obtained SPEEK was directly exchanged to its $\mathrm{Na}$-ion form, referred to as $\mathrm{Na}-\mathrm{SPEEK}$, in $2 \mathrm{M} \mathrm{NaOH}$ solution in water. Ion exchange with $\mathrm{Li}^{+}, \mathrm{K}^{+}, \mathrm{Zn}^{2+}$, and $\mathrm{Mg}^{2+}$ was performed by prolonged immersion of the Na-SPEEK in the respective chloride solution in water, resulting in the corresponding ionomer, referred to as Li-SPEEK, K-SPEEK, $\mathrm{Zn}$-SPEEK, and Mg-SPEEK. While the chemical structure of the polymer as revealed by ${ }^{1} \mathrm{H}$ NMR and Fourier transform infrared (Figure S1) is in agreement with previous literature reports, ${ }^{19,20}$ the DS could be determined by elemental microanalysis. For the present study, two different SPEEK samples have been used; one with a moderate DS (DS = 63\%)-referred to as SPEEK-63 and the second with a high DS (DS $=93 \%$ )-referred to as SPEEK-93. SPEEK samples with lower DS $(<50 \%)$ were not considered because they are insoluble in most organic solvents and thus membrane fabrication was not possible. All of the data presented here correspond to SPEEK with DS of 63\% unless otherwise mentioned.

Thin films of M-SPEEK ( $\mathrm{M}=\mathrm{Li}, \mathrm{Na}, \mathrm{K}, \mathrm{Mg}$, and $\mathrm{Zn}$ ) were casted from their respective solution in $\mathrm{N}, \mathrm{N}$-diethylacetamid (DMAc) on a glass substrate. Subsequent drying of the films resulted in dense membranes (Figure S3), which upon soaking in liquid organic carbonate showed extremely poor metal ion conductivities (see below). Note that a sufficient solvent uptake is necessary because the dry membranes are ionically blocking, so they behave like an ionic insulator (Figure S4). In water, the dense SPEEK membrane can swell up, creating percolation pathways for proton conduction $\left(\mathrm{H}^{+}\right.$conductivity: $10-50 \mathrm{mS} \mathrm{cm}{ }^{-1}$ ) between the hydrophilic clusters. However, aprotic organic solvents are absorbed insufficiently by the dense M-SPEEK membranes, leading to poor solvation and mobility of the metal ions. Fluoropolymers like Nafion, where 
the fluorinated polymer backbone is relatively more hydrophobic, can swell up in polar organic solvents, which facilitates dissociation and transport of metal ions. Thus, a common strategy in the development of solid-liquid hybrid ionomers is the preparation of a polymer blend consisting of a large amount (equal or more) of fluoropolymer like PVDF with the active ionomer to enhance the organic solvent intake. ${ }^{15}$ Another strategy is the introduction of perfluorosulfonated groups in the anionic functionality, which not only improve organic solvent intake but also promote cation dissociation. ${ }^{9,13,21-23}$ However, the latter strategy typically involves a complex synthesis. Because our goal is to move away from expensive fluoropolymers, we have developed a simple but versatile approach to fabricate high ionic conductivity ionomer membranes.

Our strategy relies on the design of high surface area porous membranes, which were obtained by directly immersing the casted polymer films into a solvent bath followed by drying (Figure S3). This technique is known as phase inversion via immersion precipitation in membrane fabrication. ${ }^{24,25}$ The solvent in the bath, called nonsolvent, differs from the solvent used (DMAc) in the casting solution. During the immersion, the nonsolvent penetrates into the polymer solution, separating it into a solid polymer phase and a liquid solvent phase. The phase separation and the mixing of the liquid solvent phase (DMAc) with the nonsolvent creates defined porosity within the membrane. However, fast solvent exchange and rapid phase separation result in a nonuniform pore-size distribution and a dense skin layer. ${ }^{26-28}$ Therefore, an optimal combination of the casting solution and the nonsolvent was necessary to obtain membranes with high porosity and porous skin layers, which are extremely crucial for solvent adsorption and a good ionic conductivity (see below). Membranes casted from a 15 wt \% solution of Na-SPEEK-63 and Na-SPEEK-93 in DMAc followed by subsequent immersion in 1-butanol displayed ideal properties. Figure 1c shows an optical image of freestanding Na-SPEEK-63 membranes cut into circular discs of $11 \mathrm{~mm}$ diameter. Interestingly, while the dense membranes are optically transparent (Figure S2), the porous ones appear white as they scatter light. The scanning electron microscopy (SEM) micrograph in Figure 1c reveals the interconnected porous structure of the membrane. Uniform and hierarchical nature of the porous structure across the whole membrane thickness is further evident from Figures 1d and S5, which show the SEM micrographs of the cross section. However, the true nature of the porosity was revealed by BrunauerEmmet-Teller (BET) analysis as presented in Figure 1e (and Figure S6). A large fraction of pores are around $4-5 \mathrm{~nm}$, which together with meso-/macro-pores of up to $\sim 80 \mathrm{~nm}$ in diameter result in relatively large cumulative surface areas $\left(\sim 35 \mathrm{~m}^{2} \mathrm{~g}^{-1}\right)$. Interconnectivity of these small pores with larger macropores $(\geq 100-200 \mathrm{~nm})$ creates a high surface area porous network that enhances the number of $-\mathrm{SO}_{3}{ }^{-} \mathrm{M}^{+/ 2+}\left(\mathrm{M}^{+/ 2+} / \mathrm{Li}^{+} / \mathrm{Na}^{+} /\right.$ $\left.\mathrm{K}^{+} / \mathrm{Zn}^{2+} / \mathrm{Mg}^{2+}\right)$ moieties in contact with the infused organic solvent, increasing the number of metal ions contributing to the ion conduction process. For simple geometric reason the large diameter pores $(>100-200 \mathrm{~nm})$ visible in the SEM micrographs contribute only nominally to the overall surface area. However, these large pores are essential for efficient solvent infusion and thus the enhancement of the ionic conductivity. The interconnected porous structure throughout the whole membrane enables an uptake of up to $76 \mathrm{wt} \%$ of the organic solvent mixture EC-DEC $(1: 1 \mathrm{v} / \mathrm{v})$. This is 25 times higher than the amount typically adsorbed by the dense membrane (3 wt \%), which displays a small surface area of $\sim 7$ $\mathrm{m}^{2} \mathrm{~g}^{-1}$. The pore-size analysis of the dense membrane (Figure S6) reveals the presence of the same $4-5 \mathrm{~nm}$ mesopores, as observed for the porous membranes, hinting that the small mesopores arise during solvent evaporation. Yet, their population is rather low in the dense membrane, and in the absence of large meso-/macro-pores, majority of these most likely remain inaccessible for solvent infusion, resulting in poor ionic conductivities (see below). Therefore, to ensure a highly interconnected porous structure, the membrane preparation conditions had to be optimized. Casting solutions with higher SPEEK contents (20, and 25 wt \%) and other nonsolvents resulted in less porous membranes (Figures S7, S8, and Table S2), which highlights the influence of the casting solution concentration and the properties of the nonsolvent on the porosity of the membrane.

Interestingly, membranes obtained from other M-SPEEK polymers (i.e., $\mathrm{M}=\mathrm{Li}, \mathrm{K}, \mathrm{Zn}$, and $\mathrm{Mg}$ ) by the phase inversion method were less porous than the Na-SPEEK ones. This is not surprising as the nature of the counter cation in M-SPEEK strongly influences its interaction with the solvent (DMAc) and the nonsolvent (butanol) and thus the phase inversion kinetics and the porosity of the resultant ionomer membranes. Therefore, freestanding porous M-SPEEK membranes for $M=$ $\mathrm{Li}, \mathrm{K}, \mathrm{Zn}$, and $\mathrm{Mg}$ were directly obtained from $\mathrm{Na}$-SPEEK membranes through ion exchange in aqueous metal chloride solutions (2 M). Complete Na-ion exchange and composition of the membranes were unequivocally confirmed by energydispersive X-ray spectroscopy (EDX) (Table S3 and Figure S9) and quantitative ICP-OES (inductively coupled plasma optical emission spectroscopy) analysis (Table S4). A complete ion exchange is possible as the aqueous solution can spontaneously percolate into the highly porous polymeric network, minimizing the ion diffusion length to $\sim 0.5 \mu \mathrm{m}$, the dimension (macroscopic) of the polymer filaments constituting the ionomer membrane. More importantly, the Na-SPEEK membranes undergo mild swelling in aqueous solution as a result of water infusion, which ensures a fast and complete ion exchange in the bulk of the polymer. The ion-exchange process did not disturb the interconnected porous structure (Figures $\mathrm{S} 6$ and S10), and as a result, the M-SPEEK membranes ( $\mathrm{M}=$ $\mathrm{Li}, \mathrm{K}, \mathrm{Mg}$, and $\mathrm{Zn}$ ) display nearly identical solvent (organic carbonates) soaking behavior as the parent Na-SPEEK.

The mechanical properties of the membranes were analyzed by mechanical tensile testing. The Young's modulus of a dry Na-SPEEK-63 membrane is $322 \pm 49 \mathrm{MPa}$, the tensile strength is $8.3 \pm 0.7 \mathrm{MPa}$, and the elongation at break is 18.0 $\pm 3.3 \%$. Upon soaking in EC-DEC $(1: 1 \mathrm{v} / \mathrm{v})$, the mechanical strength weakens, as evident from the Young's modulus of 23 $\pm 6 \mathrm{MPa}$ and the tensile strength of $1.1 \pm 0.2 \mathrm{MPa}$. However, the elongation at break increases to $176.9 \pm 21.2 \%$ because of higher ductility of the soaked membrane. Similar results were obtained for Li/Zn-SPEEK membranes (Table S5). Notably, these values are significantly higher than the mechanical properties of Nafion membranes. ${ }^{29,30}$ The thermal stability of SPEEK membranes were analyzed by thermogravimetric analysis (TGA), as shown in Figure S11. All of the MSPEEK materials are thermally stable up to $450{ }^{\circ} \mathrm{C}$ which is in good agreement with previously reported literature. ${ }^{19}$ Good thermal stability of the EC-DEC-soaked ionomer membranes was confirmed by flame testing (Figure S12). While Celgard soaked in EC-DEC burn and collapses in a second, the 

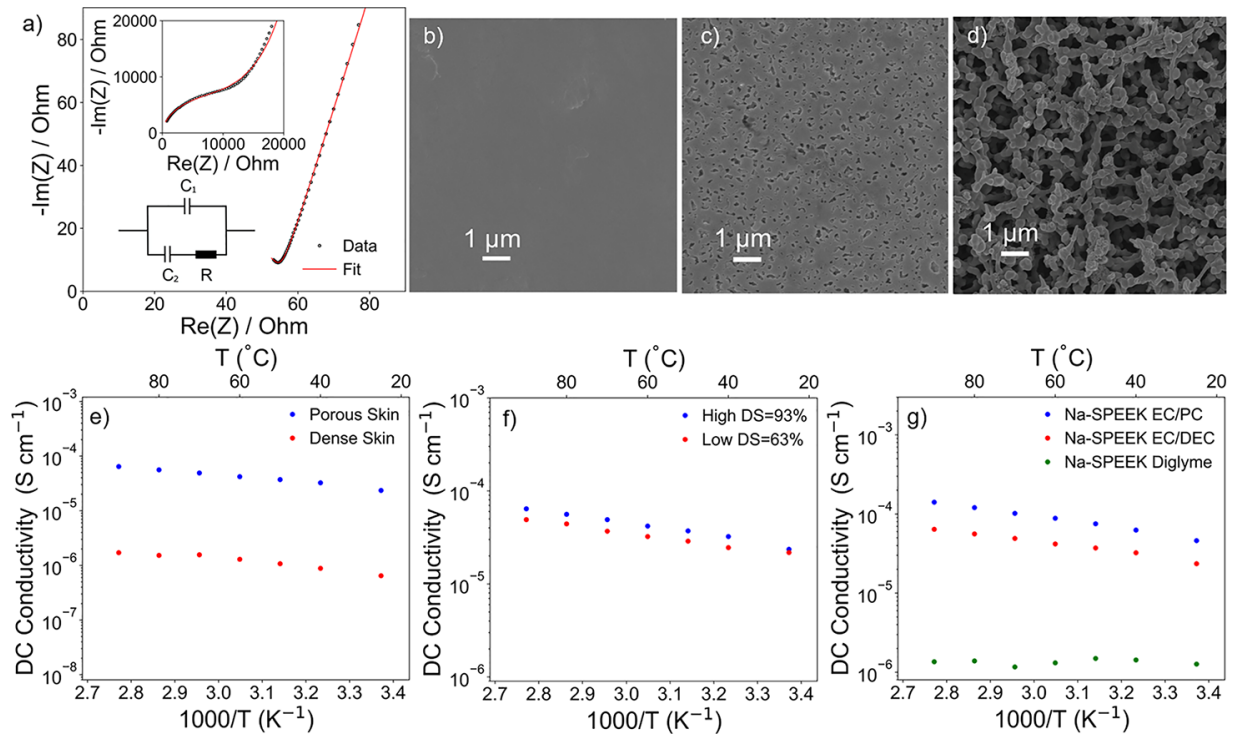

Figure 2. Effect of membrane porosity, DS, and solvent on the ionic conductivity. (a) Nyquist impedance plots for a porous Na-SPEEK-93 membrane vis-à-vis a dense one (upper left inset) infused with EC-PC $(1: 1 \mathrm{v} / \mathrm{v})$; the red line represents the fit using the equivalent circuit presented in the lower left inset. (b) SEM micrograph of the surface of a dense Na-SPEEK membrane. SEM micrographs of the surface of porous Na-SPEEK membranes with a relatively (c) dense skin layer and a (d) highly porous skin layer. (e) Variation of ionic conductivities with temperature for EC-DEC-soaked porous Na-SPEEK-93 membranes for a relatively dense skin layer vs a highly porous skin layer. (f) Temperaturedependent ionic conductivities of EC-DEC-soaked porous Na-SPEEK membranes for different (63 and 93\%) degrees of sulfonation. (g) Temperature-dependent ionic conductivities of porous Na-SPEEK-93 membranes for EC-PC (1:1 v/v), EC-DEC (1:1 v/v), and diglyme infusion.

ionomer membrane is less readily combustible and maintains its shape for longer.

Ionic Conductivity. The ionic conductivity of the M$\operatorname{SPEEK}(\mathrm{M}=\mathrm{Na}, \mathrm{Li}, \mathrm{K}, \mathrm{Mg}$, and $\mathrm{Zn})$ membranes was measured in a symmetric Swagelok-type cell with two stainless steel blocking electrodes. The used membranes were all around $50 \mu \mathrm{m}$ in thickness. The conductivity was calculated by fitting the impedance data with an equivalent circuit, shown in Figure 2a (lower inset). Figure 2a shows the Nyquist impedance plot for a porous $\mathrm{Na}$-SPEEK membrane vis-à-vis a dense $\mathrm{Na}$ SPEEK membrane (upper inset) infused with EC-PC mixture $(1: 1 \mathrm{v} / \mathrm{v})$. The dense membrane (Figure $2 \mathrm{~b}$ ) shows a very large semicircle, which is the result of a very poor Na-ionic conductivity $\left(2 \times 10^{-8} \mathrm{~S} \mathrm{~cm}^{-1}\right)$. On the contrary, the porous Na-SPEEK membrane (Figure 2d) infused with EC-PC shows nearly fourfold higher Na-ion conductivity of $0.7 \times 10^{-4}$ $\mathrm{S} \mathrm{cm}{ }^{-1}$, which is comparable to high lithium ion conductivity displayed by lithium exchanged Nafion upon PC infusion. ${ }^{9}$ It is well known that the rigid backbone in solid polymer electrolytes does not allow local segmental motion, ${ }^{31,32}$ which is required for good ionic conductivity. One way to overcome that is by plasticizing the polymer through organic solvent infiltration. However, poor hydrophobicity of the PEEK backbone results in inadequate aprotic solvent percolation, leading to limited dissociation and transport of the sodium ions. In comparison, the hierarchically porous $\mathrm{Na}$ SPEEK membrane adsorbs relatively large amount of solvent (76 wt \%). Furthermore, the microstructure of the pore wall is expected to be decorated with $-\mathrm{SO}_{3}{ }^{-} \mathrm{Na}^{+}$clusters because of the hydrogen bonding between sulfonate groups and 1-butanol during the pore formation. These effects lead to facile dissociation of $\mathrm{Na}^{+}$and their enhanced transport through the organic solvent-filled nanochannels of the porous Na-SPEEK membrane. For high ionic conductivity, the M-SPEEK membrane has to fulfill three main criteria. First, a high surface area is needed to increase the number of $-\mathrm{SO}_{3}{ }^{-} \mathrm{Na}^{+}$ moieties in contact with the organic solvent; second, a high DS to increase to total number of charge carriers; and third, interconnected porous network and a highly porous skin layer to ensure good infusion of the solvent and wetting of the entire membrane (Table S6).

Figure 2e compares the ionic conductivity of two porous $\mathrm{Na}$ SPEEK-93 membranes infused with EC-DEC $(1: 1 \mathrm{v} / \mathrm{v})$ in the temperature range $25-90{ }^{\circ} \mathrm{C}$. The membrane with a porous skin layer (Figure $2 \mathrm{~d}$ ) has a $\mathrm{Na}$-ion conductivity that is 2 orders of magnitude higher than the $\mathrm{Na}$-ion conductivity of a similarly porous membrane but with a relatively dense skin layer (Figure 2c). A porous surface facilitates wetting of the whole membrane, which leads to a higher ionic conductivity as explained above. Influence of the DS on the ionic conductivity is evident from Figure $2 \mathrm{f}$, which compares the ionic conductivity of a Na-SPEEK-93 versus a Na-SPEEK-63 membrane. As expected, higher DS results in a slightly higher $\mathrm{Na}$-ion conductivity because of an increase in the number of charge carriers with increasing DS. Besides membrane properties, the infused solvent was also found to have an influence on the ionic conductivity. Figure $2 \mathrm{~g}$ displays the ionic conductivities of Na-SPEEK-93 membranes infused with different organic solvents. The membrane infused with ECPC $(1: 1 \mathrm{v} / \mathrm{v})$ shows the highest $\mathrm{Na}^{+}$-ion conductivity followed by the one infused with EC-DEC $(1: 1 \mathrm{v} / \mathrm{v})$, whereas diglyme infusion leads to the lowest conductivity. Clearly, the ionic conductivity increases with increasing solvent polarity (dielectric constant) and decreasing viscosity in the order, diglyme $<$ EC-DEC $<$ EC-PC because higher solvent polarity promotes better cation dissociation and rapid transport. However, EC-DEC $(1: 1 \mathrm{v} / \mathrm{v})$ was chosen for further studies, as the difference of ionic conductivities between the membranes soaked in EC-DEC and EC-PC is not that high, and EC-DEC is known to form more stable solid 
electrolyte interphase (SEI) than EC-PC in lithium ion batteries. $^{33,34}$

Recently, there has been a huge surge in research activity on beyond Li-ion batteries, for example, battery chemistries involving metal ions like $\mathrm{K}^{+}, \mathrm{Zn}^{2+}$, and $\mathrm{Mg}^{2+} \cdot{ }^{5-38}$ Thus, it was interesting to explore the ambitious but exciting prospect of turning a $\mathrm{Na}^{+}$-conducting ionomer into $\mathrm{Li}^{+}, \mathrm{K}^{+}, \mathrm{Zn}^{2+}$, and $\mathrm{Mg}^{2+}$ ionomers. Figure $3 \mathrm{a}$ compares the ionic conductivity of

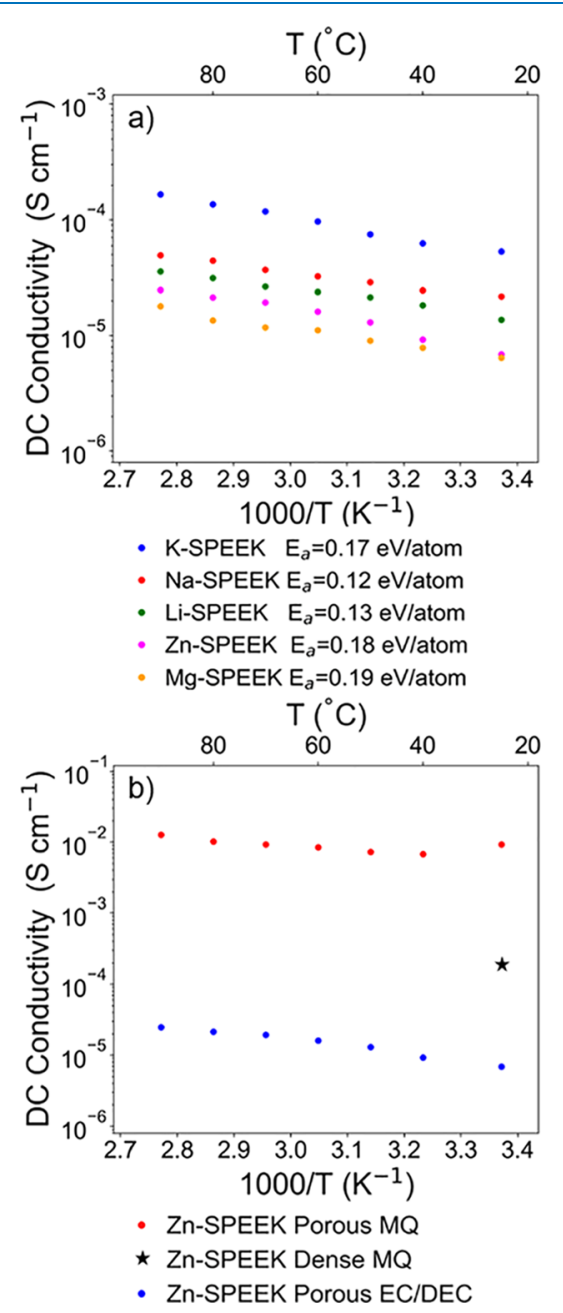

Figure 3. (a) Temperature-dependent ionic conductivities of porous M-SPEEK membranes $(\mathrm{M}=\mathrm{Na}, \mathrm{Li}, \mathrm{K}, \mathrm{Zn}$, and $\mathrm{Mg})$ infused with EC-DEC $(1: 1 \mathrm{v} / \mathrm{v})$. (b) Ionic conductivities as a function of temperature for porous $\mathrm{Zn}$-SPEEK membranes soaked in EC-DEC and MQ water. The star symbol in (b) designates the ionic conductivity of dense $\mathrm{Zn}$-SPEEK membrane infused with water.

the corresponding ionomer membranes, soaked in EC-DEC (v/v 1:1). All of the ionomer membranes had identical DS (DS $=63 \%$ ), similar pore distribution, and surface area (Figure S6). The monovalent ionomers, that is, Li-SPEEK, Na-SPEEK, and K-SPEEK demonstrate higher ion conductivities than the divalent ionomers Mg-SPEEK and Zn-SPEEK. Such behavior can be explained by stronger solvation of the smaller (thus, high charge density) divalent cations, which hinders fast ionic diffusion in the carbonate solvent. To understand this effect further, the activation energies for the ion mobility in the soaked membranes were calculated by fitting the temperaturedependent ionic conductivity data with the modified Arrhenius equation (eq 3, Methods) (Figure S13). As anticipated, the divalent ionomers $\mathrm{Mg}$-SPEEK and $\mathrm{Zn}$-SPEEK display relatively higher activation energies $\left(E_{\mathrm{a}}\right)$ of 0.19 and $0.18 \mathrm{eV}$ atom $^{-1}$, respectively, compared with Na-SPEEK $\left(E_{\mathrm{a}}=0.12 \mathrm{eV}\right.$ atom $\left.^{-1}\right)$ and Li-SPEEK $\left(E_{\mathrm{a}}=0.13 \mathrm{eV}\right.$ atom $\left.^{-1}\right)$. The solvation effect can also explain the ionic conductivity trend among the monovalent ionomers where the ionic conductivity increases from $\mathrm{Li}^{+}$to $\mathrm{Na}^{+}$to $\mathrm{K}^{+}$, in the order of their respective size. The smaller size of the solvated $\mathrm{K}^{+}$ion leads to faster diffusion and hence K-SPEEK shows the highest room temperature ionic conductivity of $0.5 \times 10^{-4} \mathrm{~S} \mathrm{~cm}^{-1}$ in EC-DEC, which increases to $1.2 \times 10^{-4}$ at $80{ }^{\circ} \mathrm{C}$. This observation agrees well with binary salt organic (liquid) electrolytes, where the $\mathrm{K}^{+}$system displays the highest ionic conductivity. ${ }^{39,40}$ Interestingly, KSPEEK exhibits an anomalous activation energy value of 0.17 $\mathrm{eV}$ atom $^{-1}$, which is higher than those of Na-SPEEK and LiSPEEK. This can be explained by increasing carrier concentration (i.e., $\mathrm{K}^{+}$) in the electrolyte with increasing temperature, which contributes an entropy term to the activation energy determined from the slope of the Arrhenius plot (Figure S13). In simpler words, for the K-SPEEK ionomer membrane, the entropy factor seems to have an influence on the activation process, in addition to the commonly considered enthalpy.

Aqueous zinc batteries, particularly those using near neutral aqueous electrolytes have attracted tremendous attention in recent years. ${ }^{41}$ However, unrestricted nucleation and growth of zinc from binary aqueous electrolytes can lead to similar dendritic issues as with alkali metals in organic electrolytes. ${ }^{6,42,44}$ Figure $3 \mathrm{~b}$ shows the $\mathrm{Zn}^{2+}$-ion conductivity of a $\mathrm{Zn}$ SPEEK membrane infused with Milli-Q (MQ) water, which demonstrates a very high conductivity of $\sim 10^{-2} \mathrm{~S} \mathrm{~cm}^{-1}$ at room temperature. This is only four times inferior to $1 \mathrm{M} \mathrm{ZnSO}_{4}$ in $\mathrm{H}_{2} \mathrm{O}\left(4 \times 10^{-2} \mathrm{mS} \mathrm{cm}^{-1}\right)$ and more than 3 orders of magnitude higher than a $\mathrm{Zn}$-SPEEK membrane infused with EC-DEC. Furthermore, increasing the temperature had little influence on the ionic conductivity, demonstrating facile dissociation of $\mathrm{Zn}$-ions and their rapid transport in water because of the high dielectric constant and low viscosity of water. It is important to note that the dense $\mathrm{Zn}$-SPEEK membrane depicts 2 orders of magnitude lower ionic conductivity (Figure 3b) than the porous one, which is explainable by only $32 \%$ water uptake by the dense membrane vis-à-vis $63 \%$ by the porous analogue. This observation further highlights the crucial role of the hierarchical porous design in achieving a very high metal ion conductivity.

Transference Number. To confirm the single-ion conductivity feature of the M-SPEEK membranes, the cation transference number was determined by using the BruceVincent method. ${ }^{43}$ Typically, a $\mathrm{Na} / \mathrm{Li} / \mathrm{Zn}$-SPEEK membrane soaked in the desired solvent (or solvent mixture) was sandwiched between two corresponding metal foils and the current-time response was measured under a constant $\mathrm{dc}$ bias potential of $20 \mathrm{mV}$. The measured initial current $I_{0}$ reflects the movement of both cations and anions, while the final steadystate current $I_{\mathrm{ss}}$ results exclusively from the motion of cations. By measuring the impedance response of the symmetric cell before and after the polarization experiment, the transference number $t_{\mathrm{M}^{+}}\left(\mathrm{M}^{+}=\mathrm{Na}^{+}, \mathrm{Li}^{+}, \mathrm{Zn}^{2+}\right)$ can be calculated from eq 4 (see Methods). Because alkali metals are highly reactive to most organic solvents including EC-DEC, ${ }^{34,44,45}$ even without the applied polarization the interfacial impedance was found to increase significantly with time because of the formation of the passivating SEI. The impedance corresponding to the ionic 

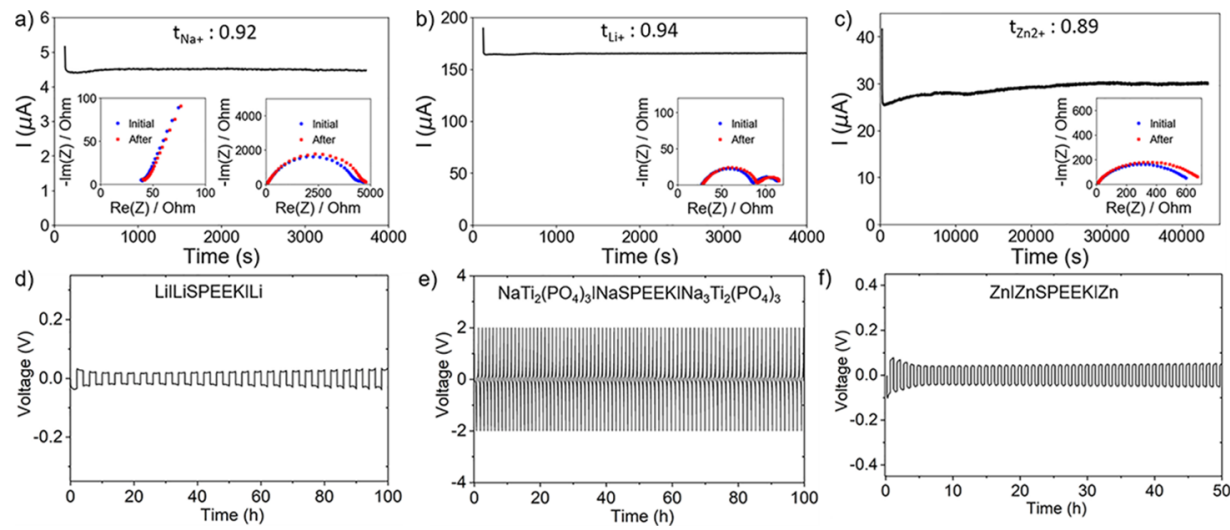

Figure 4. Current-time profiles and the impedance spectra (inset) taken before and after the voltage polarization $(20 \mathrm{mV})$ for (a) $\mathrm{Na} / \mathrm{Na}$ symmetric cell with Na-SPEEK soaked in EC-DEC ( $1: 1 \mathrm{v} / \mathrm{v}),(\mathrm{b}) \mathrm{Li} / \mathrm{Li}$ symmetric cell with Li-SPEEK soaked in EC-DEC, and (c) Zn/Zn symmetric cell with $\mathrm{Zn}$-SPEEK soaked in MQ water. Voltage versus time profiles for (d) Li/Li symmetric cell with EC-DEC (1:1 v/v) soaked LiSPEEK membrane, for $2 \mathrm{~h} \mathrm{Li}$ plating/stripping at a current density of $250 \mu \mathrm{A} \mathrm{cm}{ }^{-2}$; (e) $\mathrm{NaTi}_{2}\left(\mathrm{PO}_{4}\right)_{3} / \mathrm{Na}_{3} \mathrm{Ti}_{2}\left(\mathrm{PO}_{4}\right)_{3}$ symmetric cell with ECDEC-soaked Na-SPEEK membrane at a current density of $200 \mu \mathrm{A} \mathrm{cm}^{-2}$; (f) $\mathrm{Zn} / \mathrm{Zn}$ symmetric cell with MQ water-soaked Zn-SPEEK membrane.

conductivity of the membrane, however, stayed unchanged. Interestingly, SEI formation behavior of $\mathrm{Na}$ and $\mathrm{Li}$ metal are very different. ${ }^{46}$ It is understood that Na-SEIs have much lower ionic conductivities $\left(\mathrm{Na}^{+}\right)$compared with Li-SEIs. This was true in our case as the interfacial SEI impedance with $\mathrm{Li}$ SPEEK was much smaller compared to the Na-SPEEK cell, with EC-DEC as the solvent. A low ionic conductivity within the SEI acts like a bottle-neck and leads to a higher overall impedance for the whole cell. Consequently, it was not possible to measure the $\mathrm{Na}^{+}$transference number $t_{\mathrm{Na}^{+}}$at room temperature, and the measurements were performed in an oven at $80{ }^{\circ} \mathrm{C}$. Figure $4 \mathrm{a}$ shows the current response to the applied polarization and the cell impedance before and after the polarization, for a $\mathrm{Na}$-SPEEK membrane soaked in ECDEC $(1: 1 \mathrm{v} / \mathrm{v})$ sandwiched between two Na-metal electrodes. Although, the measurements were done at $80^{\circ} \mathrm{C}$, the overall impedance because of the SEI still remains quite high. The semicircle corresponds to the impedance of the Na-SEI before and after the polarization measurement. The initial resistance of $38 \Omega$, at the real axis intercept, corresponds to the ionic conductivity of the Na-SPEEK membrane at $80{ }^{\circ} \mathrm{C}$. On the basis of these results, the transference number for the $\mathrm{Na}$ SPEEK membrane $\left(t_{\mathrm{Na}^{+}}\right)$was calculated to be 0.92 (see Table S7). For better comparison, the $\mathrm{Li}^{+}$transference number $\left(t_{\mathrm{Li}^{+}}\right)$ was measured under the same conditions as $t_{\mathrm{Na}^{+}}$. Figure $4 \mathrm{~b}$ shows the current response to the applied voltage polarization $(20 \mathrm{mV})$ and the cell impedance before and after the polarization. Unlike Na-SPEEK, two impedance semicircles appear for the SEI with Li-SPEEK but the overall SEI impedance is about 40 times smaller than that for Na-SPEEK. The high-frequency resistance of $27 \Omega$ corresponds to the ionic conductivity of the Li-SPEEK membrane at $80{ }^{\circ} \mathrm{C}$. These results lead to a Li transference number $\left(t_{\mathrm{Li}^{+}}\right)$of 0.94 for the LiSPEEK in EC-DEC. Compared with $\mathrm{Li}$ - and Na-metal electrodes, SEI formation is not an issue with zinc because of its relatively low electrochemical potential. Therefore, the $\mathrm{Zn}^{2+}$ transference number measurement could be carried out at room temperature. Figure $4 c$ shows the current response to the voltage polarization and the cell impedance before and after the polarization for a $\mathrm{Zn}$-SPEEK membrane soaked in MQ water. Although, SEI formation is not an issue, the overall high impedance stems from a native $\mathrm{ZnO}$ layer on the $\mathrm{Zn}$ electrodes. ${ }^{47}$ The transference number for the Zn-SPEEK membrane $\left(t_{\mathrm{Zn}^{2+}}\right)$ was calculated to be 0.89 . As expected based on the chemistry of the electrolyte system, all of the ionomer systems display very high metal ion transference numbers, confirming their single-ion conductivity characteristic in binary salt-free liquid solvents. The small deviations from the unity value most likely reflect the retention of some mobile anionic species in the membranes during the synthesis and fabrication steps.

Preliminary electrochemical studies of reversible metal ion transport through the ionomer membranes are presented in Figure $4 \mathrm{~d}-\mathrm{f}$. Reversible Li plating/stripping through an ECDEC-soaked Li-SPEEK membrane is evident from Figure $4 \mathrm{~d}$. A current density of $250 \mu \mathrm{A} \mathrm{cm}^{-2}$ was applied with a capacity limitation of $0.5 \mathrm{~mA} \mathrm{~h}$ for plating/stripping. When employed as an electrolyte in a full cell with a $\mathrm{Li}$ anode and $\mathrm{LiFePO}_{4}$ as the positive host, stable charge-discharge cycling performance was observed, delivering a steady capacity of $120 \mathrm{~mA} \mathrm{~h} \mathrm{~g}^{-1}$ at a $1 \mathrm{C}$ rate (Figure S14). Because of the very high impedance of the SEI layer for the EC-DEC with Na metal (see above), feasibility of reversible $\mathrm{Na}^{+}$cycling through Na-SPEEK membrane was studied between two $\mathrm{Na}_{x} \mathrm{Ti}_{2}\left(\mathrm{PO}_{4}\right)_{3}(\mathrm{NTP} ; x$ $=1$ and 3 ) electrodes. NTP has a relatively low electrochemical potential and does not trigger the carbonate electrolyte decomposition and thus SEI formation at the electrode interface, which allows the reversible cycling of $\mathrm{Na}$ ions as shown in Figure 4e. A reversibly capacity of $0.15 \mathrm{~mA} \mathrm{~h}$ is delivered at a current density of $200 \mu \mathrm{A} \mathrm{cm}{ }^{-2}$ with unaltered voltage polarization over many cycles. Figure $4 \mathrm{f}$ shows the reversible voltage response of a MQ-water-soaked $\mathrm{Zn}$-SPEEK membrane under a current density of $1 \mathrm{~mA} \mathrm{~cm}{ }^{-2}$ for a zinc plating/stripping capacity of $0.5 \mathrm{~mA}$ h. In the first few cycles, a decrease in overpotential is observed, which most likely corresponds to the removal of the native $\mathrm{ZnO}$ layer from the $\mathrm{Zn}$ electrodes. ${ }^{48}$ The high current density of $1 \mathrm{~mA} \mathrm{~cm}{ }^{-2}$ could be applied because of the very high ionic conductivity of $\mathrm{Zn}$ SPEEK soaked in water (Figure $3 \mathrm{~b}$ ). The $\mathrm{Zn}$-SPEEK- $\mathrm{H}_{2} \mathrm{O}$ also displays excellent electrochemical stability, exceeding $3 \mathrm{~V}$ (Figure S15a), which is similar to the "water in salt" electrolyte system. ${ }^{49}$ In comparison, EC-DEC-infused Li-SPEEK demonstrates modest electrochemical stability in $0-5 \mathrm{~V}$ window versus $\mathrm{Li}$ (Figure S15b); however. the effect of EC-DEC decomposition at lower potentials is also apparent. It is important to note that the main goal of this study is to 
demonstrate the development of versatile ionomer membranes based on a simple and inexpensive polymer, not their optimization for alkali metal battery applications.

\section{CONCLUSION}

Development of hierarchically porous polymer membranes with versatile ion conduction can be challenging. Here, we report on a template-free synthesis of porous ionomer membranes from sulfonated PEEK through a phase inversion method. An interconnected porous network along with high surface area enables efficient solvent infusion, which is necessary to promote facile cation dissociation and their rapid transport. Such a membrane, made of a simple nonfluorinated polymer like SPEEK is capable of versatile ion $\left(\mathrm{Li}^{+}, \mathrm{Na}^{+}, \mathrm{K}^{+}, \mathrm{Mg}^{2+}\right.$, and $\left.\mathrm{Zn}^{2+}\right)$ conduction, resulting in diverse ionomer membranes. While alkali-SPEEK membranes infused with liquid organic carbonates reach ionic conductivities up to $\sim 10^{-4} \mathrm{~S} \mathrm{~cm}^{-1}$ at room temperature, $\mathrm{Zn}$-SPEEK infused with water displays an unprecedented ionic conductivity of $\sim 10^{-2} \mathrm{~S} \mathrm{~cm}^{-1}$. The former value is comparable to that of Li-Nafion membranes infused with $\mathrm{PC}$, and the latter one marginally falls short of the conductivity of $1 \mathrm{M} \mathrm{ZnSO}_{4}$ in water. These conductivity values are several orders of magnitude higher than those for the dense SPEEK membranes. Although several high conductivity $\mathrm{Li}$ ionomers have been reported to date, $\mathrm{Na}$ and $\mathrm{K}$ ionomers with good ionic conductivities are rare, and dicationic ionomeres with our reported conductivities are nonexistent. Besides, all ionomers display near unity metal ion transference numbers, and feasibility of reversible metal ion cycling through the ionomer membranes is demonstrated. Overall, the presented findings have the prospect to inspire a new avenue of ionomer membrane development with high single-metal ion conductivity from simple and inexpensive polymers.

\section{EXPERIMENTAL METHODS}

Synthesis of SPEEK. Details regarding the synthesis of SPEEK and its characterization by NMR can be found in the Supporting Information.

Membrane Fabrication. A 15 wt \% solution of Na-SPEEK in DMAc was casted onto a glass plate via doctor blading with a casting speed of $15 \mathrm{~mm} \mathrm{~s}^{-1}$ and a casting gap of $50-200 \mu \mathrm{m}$. The casted film was immediately immersed into a bath of butanol for $20 \mathrm{~min}$. The resulting porous Na-SPEEK membrane was carefully detached from the glass plate, dried at $200{ }^{\circ} \mathrm{C}$ under vacuum for $12 \mathrm{~h}$, and directly transferred to an argon filled glove box. Typically, membranes of thickness between 20 and $100 \mu \mathrm{m}$ were obtained depending on the casting gap, but $50 \mu \mathrm{m}$ thick membranes were applied in all studies. The dried membranes were punched into circular disks (11 $\mathrm{mm}$ in diameter). Prior to use, the membrane disks were immersed in the respective solvent/solvent mixtures for at least $12 \mathrm{~h}$. SPEEK membranes with $\mathrm{Li}^{+}, \mathrm{K}^{+}, \mathrm{Zn}^{2+}$, and $\mathrm{Mg}^{2+}$ as the counter cation, referred to as Li-SPEEK, K-SPEEK, Zn-SPEEK, and Mg-SPEEK were obtained by immersing Na-SPEEK membranes in a $2 \mathrm{M}$ aqueous $\mathrm{LiCl}, \mathrm{KCl}, \mathrm{MgCl}_{2}$, or $\mathrm{ZnCl}_{2}$ solution, respectively, for $12 \mathrm{~h}$ before profusely washing with MQ water.

Membrane Characterization. The DS, which is defined as the ratio of sulfonated to nonsulfonated PEEK units, was determined by elemental microanalysis according to

$$
\mathrm{DS}=\frac{19 M_{\mathrm{C}} m_{\mathrm{S}}}{M_{\mathrm{S}} m_{\mathrm{C}}} \times 100
$$

where $M_{\mathrm{C}}$ and $M_{\mathrm{S}}$ are the atomic weight of carbon and sulfur, respectively. The weight fraction of carbon $m_{\mathrm{C}}$ and sulfur $m_{\mathrm{S}}$ was obtained by elemental microanalysis. By calculating the ratio of sulfur atoms per PEEK unit (one PEEK unit is equal to 19 carbon atoms), the DS was obtained. SEM was performed with a LEO Gemini 1530. TGA was performed in air on a TGA/SDTA 851 from METTLER TOLEDO by applying a heating rate of $10^{\circ} \mathrm{C} \mathrm{min}{ }^{-1}$ in the temperature range $25-1100$ ${ }^{\circ} \mathrm{C}$. Mechanical tensile testing of dry and wet membranes was performed on a Shimadzu (Autograph AGS-X). The membranes were cut into dog-bone-shaped specimens and then pulled apart under ambient conditions. Stress-strain curves were obtained at a crosshead speed of $2 \mathrm{~mm} \mathrm{~min}^{-1}$ and an initial load of $0.02 \mathrm{~N}$ using Trapezium $\mathrm{X}$ software. The surface area was determined by the BET analysis of the nitrogen adsorption-desorption isotherm recorded at $77 \mathrm{~K}$ on a Quantachrome AUTOSORB-iQ. Density functional theory (DFT) analysis was applied on the adsorption branch of the isotherm to determine the pore-size distribution and pore volume. $^{50}$ The solvent uptake of the membranes was measured by immersing them in an EC-DEC $(1: 1 \mathrm{v} / \mathrm{v})$ solution for 12 h. The solvent uptake SU (wt \%) was calculated according to

$$
\mathrm{SU}=\frac{100}{m_{\mathrm{wet}}} \times\left(m_{\mathrm{wet}}-m_{\mathrm{dry}}\right)
$$

where $m_{\text {wet }}$ and $m_{\text {dry }}$ are the weight of the wet and dry membrane, respectively.

Ionic Conductivity. The soaked $(12 \mathrm{~h})$ ionomer membrane was mounted in a symmetric Swagelok-type cell, sandwiched between two stainless steel rods. The resistance of the membrane was measured using a two probe ac impedance spectroscopy (VMP3, Biologic) in the frequency range from $400 \mathrm{kHz}$ to $100 \mathrm{mHz}$ with a potentiostatic signal perturbation of $10 \mathrm{mV}$. The ionic conductivities at different temperatures were obtained by fitting the Nyquist plot using EC-lab Z-fit analysis software. The activation energy for Li-, Na-, $\mathrm{K}-, \mathrm{Mg}$-, and $\mathrm{Zn}$-ion diffusion was obtained by linear fitting of the ionic conductivity values applying the modified Arrhenius equation

$$
\sigma T=\sigma_{0} \exp \left(\frac{-E_{\mathrm{a}}}{k_{\mathrm{b}} T}\right)
$$

where $\sigma$ is the temperature-dependent ionic conductivity, $\sigma_{0}$ is the ionic conductivity at absolute zero temperature, $E_{\mathrm{a}}$ is the activation energy of ion diffusion, $k_{\mathrm{b}}$ is Boltzmann constant, and $T$ is the temperature.

Transference Number. According to the method of Evans et al. using eq 4 , the ion transference number $t_{+}$was calculated. $^{43}$

$$
t_{+}=\frac{I_{\mathrm{ss}}\left(\Delta V-I_{0} R_{0}\right)}{I_{0}\left(\Delta V-I_{\mathrm{ss}} R_{\mathrm{ss}}\right)}
$$

where $I_{0}$ and $I_{s s}$ are the currents in the unpolarized and polarized states, respectively, $R_{0}$ and $R_{\mathrm{ss}}$ are the resistances in the unpolarized and polarized states, respectively, and $\Delta V$ is the potential step used in the method. The ionomer membranes Na-SPEEK-93 and Li-SPEEK-63 soaked in ECDEC $(1: 1 \mathrm{v} / \mathrm{v})$ and Zn-SPEEK-93 soaked in MQ-water were mounted in a symmetric Swagelok-type cell, sandwiched between two $\mathrm{Na}, \mathrm{Li}$, or $\mathrm{Zn}$ disks, respectively. The $\mathrm{dc}$ 
polarization experiments (using VMP3, Biologic) were conducted at an applied voltage of $20 \mathrm{mV}$ for $2 \mathrm{~h}$, and the impedance spectroscopy data were recorded before and after the polarization in the frequency range of $400 \mathrm{kHz}$ to $100 \mathrm{mHz}$ with a perturbation of $10 \mathrm{mV}$.

Electrochemical Studies. Na-SPEEK-93 and Li-SPEEK63 soaked in EC-DEC $(1: 1 \mathrm{v} / \mathrm{v})$ and Zn-SPEEK-93 soaked in MQ-water were used. The electrochemical measurements were performed using a VMP3 (Biologic) cycler. Zn stripping and plating performance was tested at a fixed current density of \pm 1 $\mathrm{mA} \mathrm{cm}{ }^{-2}$ for a capacity of $0.5 \mathrm{~mA} \mathrm{~h}$. Li stripping and plating performance was tested at a fixed current density of $\pm 250 \mu \mathrm{A}$ $\mathrm{cm}^{-2}$ and a capacity of $0.5 \mathrm{~mA} \mathrm{~h}$. Na cycling was carried out between two $\mathrm{Na}_{x} \mathrm{Ti}_{2}\left(\mathrm{PO}_{4}\right)_{3}(\mathrm{NTP} ; x=1$ and 3$)$ electrodes at a fixed current density of $\pm 200 \mu \mathrm{A} \mathrm{cm} \mathrm{cm}^{-2}$ in a potential limit of $\pm 1 \mathrm{~V}$ for a capacity of $0.15 \mathrm{~mA}$ h. Carbon-coated $\mathrm{NaTi}_{2}\left(\mathrm{PO}_{4}\right)_{3}$ was synthesized by following a literature report, ${ }^{51}$ while its electrochemical $\mathrm{Na}^{+}$intercalation resulted in the $\mathrm{Na}_{3} \mathrm{Ti}\left(\mathrm{PO}_{4}\right)_{3}$. For the $\mathrm{Li}-\mathrm{LiFePO}_{4}$ cell, a commercial $\mathrm{LiFePO}_{4}$ from MTI Corp (USA) was used. The $\mathrm{LiFePO}_{4}$ was mixed with carbon and Li-SPEEK in 70:15:15 weight ratio in $N$-methyl-2pyrrolidone to obtain a viscous slurry, which was casted on a carbon-coated $\mathrm{Al}$ foil and dried at $100{ }^{\circ} \mathrm{C}$ under vacuum to obtain the cathode. A $50 \mu \mathrm{m} \mathrm{Li}$-SPEEK membrane soaked in EC-DEC $(1: 1 \mathrm{v} / \mathrm{v})$ was placed between a $\mathrm{Li}$ anode foil and a $0.785 \mathrm{~cm}^{2}$ cathode coin (soaked in EC-DEC solvent) to assemble the full cell. The cell was galvanostatically chargeddischarged by applying a current density of $170 \mathrm{~mA} \mathrm{~g}^{-1}$ (1 C: 1 h charge/discharge).

\section{ASSOCIATED CONTENT}

\section{S Supporting Information}

The Supporting Information is available free of charge on the ACS Publications website at DOI: 10.1021/acsomega.8b03552.

SPEEK synthesis and characterizations, membrane preparation and characterizations $\left(\mathrm{N}_{2}\right.$ adsorption/ desorption analysis, SEM, EDX, ICP-OES, ionic conductivity), mechanical and thermal property analysis, and electrochemical data from a Li-LFP full cell with LiSPEEK electrolyte (PDF)

\section{AUTHOR INFORMATION}

\section{Corresponding Author}

*E-mail: dipan.kundu@mat.ethz.ch.

\section{ORCID $\odot$}

Dipan Kundu: 0000-0001-5244-9836

\section{Notes}

The authors declare no competing financial interest.

\section{ACKNOWLEDGMENTS}

We thank the Swiss National Science Foundation (SNSF) for the financial support for this work through their Ambizione grant to D.K. We also acknowledge ScopeM (ETH Zürich) for providing the SEM facilities and Dr. Bodo Hattendorf and Thomas Vonderach for the ICPOES analyses. We thank U. Lustenberger (ETH Zürich) for the valuable input on the fabrication of porous ionomer membranes.

\section{REFERENCES}

(1) Mindemark, J.; Lacey, M. J.; Bowden, T.; Brandell, D. Beyond PEO-Alternative host materials for $\mathrm{Li}+$-conducting solid polymer electrolytes. Prog. Polym. Sci. 2018, 81, 114-143.

(2) Lin, K.-J.; Li, K.; Maranas, J. K. Differences between polymer/ salt and single ion conductor solid polymer electrolytes. RSC Adv. 2013, 3, 1564-1571.

(3) Diederichsen, K. M.; McShane, E. J.; McCloskey, B. D. Promising Routes to a High $\mathrm{Li}+$ Transference Number Electrolyte for Lithium Ion Batteries. ACS Energy Lett. 2017, 2, 2563-2575.

(4) Chazalviel, J.-N. Electrochemical aspects of the generation of ramified metallic electrodeposits. Phys. Rev. A: At., Mol., Opt. Phys. 1990, 42, 7355-7367.

(5) Cheng, X.-B.; Zhang, R.; Zhao, C.-Z.; Zhang, Q. Toward Safe Lithium Metal Anode in Rechargeable Batteries: A Review. Chem. Rev. 2017, 117, 10403-10473.

(6) Tikekar, M. D.; Choudhury, S.; Tu, Z.; Archer, L. A. Design principles for electrolytes and interfaces for stable lithium-metal batteries. Nat. Energy 2016, 1, 16114.

(7) Ma, J.-1.; Meng, F.-1.; Yu, Y.; Liu, D.-p.; Yan, J.-m.; Zhang, Y.; Zhang, X.-b.; Jiang, Q. Prevention of dendrite growth and volume expansion to give high-performance aprotic bimetallic $\mathrm{Li}-\mathrm{Na}$ alloy-O2 batteries. Nat. Chem. 2018, 11, 64-70.

(8) Gao, J.; Sun, C.; Xu, L.; Chen, J.; Wang, C.; Guo, D.; Chen, H. Lithiated Nafion as polymer electrolyte for solid-state lithium sulfur batteries using carbon-sulfur composite cathode. J. Power Sources 2018, 382, 179-189.

(9) Lu, Y.; Tikekar, M.; Mohanty, R.; Hendrickson, K.; Ma, L.; Archer, L. A. Stable Cycling of Lithium Metal Batteries Using High Transference Number Electrolytes. Adv. Energy Mater. 2015, 5, 1402073.

(10) Zhang, H.; Li, C.; Piszcz, M.; Coya, E.; Rojo, T.; RodriguezMartinez, L. M.; Armand, M.; Zhou, Z. Single lithium-ion conducting solid polymer electrolytes: advances and perspectives. Chem. Soc. Rev. 2017, 46, 797-815.

(11) Piszcz, M.; Garcia-Calvo, O.; Oteo, U.; Lopez del Amo, J. M.; Li, C.; Rodriguez-Martinez, L. M.; Youcef, H. B.; Lago, N.; Thielen, J.; Armand, M. New Single Ion Conducting Blend Based on PEO and PA-LiTFSI. Electrochim. Acta 2017, 255, 48-54.

(12) Ma, Q.; Zhang, H.; Zhou, C.; Zheng, L.; Cheng, P.; Nie, J.; Feng, W.; Hu, Y.-S.; Li, H.; Huang, X.; Chen, L.; Armand, M.; Zhou, Z. Single Lithium-Ion Conducting Polymer Electrolytes Based on a Super-Delocalized Polyanion. Angew. Chem., Int. Ed. 2016, 55, 25212525.

(13) Bouchet, R.; Maria, S.; Meziane, R.; Aboulaich, A.; Lienafa, L.; Bonnet, J.-P.; Phan, T. N. T.; Bertin, D.; Gigmes, D.; Devaux, D.; Denoyel, R.; Armand, M. Single-ion BAB triblock copolymers as highly efficient electrolytes for lithium-metal batteries. Nat. Mater. 2013, 12, 452-457.

(14) Oh, H.; Xu, K.; Yoo, H. D.; Kim, D. S.; Chanthad, C.; Yang, G.; Jin, J.; Ayhan, I. A.; Oh, S. M.; Wang, Q. Poly(arylene ether)-Based Single-Ion Conductors for Lithium-Ion Batteries. Chem. Mater. 2015, 28, 188-196.

(15) Pan, Q.; Chen, Y.; Zhang, Y.; Zeng, D.; Sun, Y.; Cheng, H. A dense transparent polymeric single ion conductor for lithium ion batteries with remarkable long-term stability. J. Power Sources 2016, $336,75-82$.

(16) Wu, X.; Wang, X.; He, G.; Benziger, J. Differences in water sorption and proton conductivity between Nafion and SPEEK. J. Polym. Sci., Part B: Polym. Phys. 2011, 49, 1437-1445.

(17) Dai, W.; Shen, Y.; Li, Z.; Yu, L.; Xi, J.; Qiu, X. SPEEK/ Graphene oxide nanocomposite membranes with superior cyclability for highly efficient vanadium redox flow battery. J. Mater. Chem. A 2014, 2, 12423-12432.

(18) Shibuya, N.; Porter, R. S. Kinetics of PEEK sulfonation in concentrated sulfuric acid. Macromolecules 1992, 25, 6495-6499.

(19) Koziara, B. T.; Kappert, E. J.; Ogieglo, W.; Nijmeijer, K.; Hempenius, M. A.; Benes, N. E. Thermal Stability of Sulfonated 
Poly(Ether Ether Ketone) Films: on the Role of Protodesulfonation. Macromol. Mater. Eng. 2015, 301, 71-80.

(20) Zaidi, S. M. J.; Mikhailenko, S. D.; Robertson, G. P.; Guiver, M. D.; Kaliaguine, S. Proton conducting composite membranes from polyether ether ketone and heteropolyacids for fuel cell applications. $J$. Membr. Sci. 2000, 173, 17-34.

(21) Feng, S.; Shi, D.; Liu, F.; Zheng, L.; Nie, J.; Feng, W.; Huang, X.; Armand, M.; Zhou, Z. Single lithium-ion conducting polymer electrolytes based on poly[(4-styrenesulfonyl)(trifluoromethanesulfonyl)imide] anions. Electrochim. Acta 2013, 93, 254-263.

(22) Jangu, C.; Savage, A. M.; Zhang, Z.; Schultz, A. R.; Madsen, L. A.; Beyer, F. L.; Long, T. E. Sulfonimide-Containing Triblock Copolymers for Improved Conductivity and Mechanical Performance. Macromolecules 2015, 48, 4520-4528.

(23) Meziane, R.; Bonnet, J.-P.; Courty, M.; Djellab, K.; Armand, M. Single-ion polymer electrolytes based on a delocalized polyanion for lithium batteries. Electrochim. Acta 2011, 57, 14-19.

(24) Strathmann, H.; Kock, K. The formation mechanism of phase inversion membranes. Desalination 1977, 21, 241-255.

(25) Lalia, B. S.; Kochkodan, V.; Hashaikeh, R.; Hilal, N. A review on membrane fabrication: Structure, properties and performance relationship. Desalination 2013, 326, 77-95.

(26) Pinnau, I.; Freeman, B. D. Formation and Modification of Polymeric Membranes: Overview. Membrane Formation and Modification; American Chemical Society, 1999; pp 1-22.

(27) Smolders, C. A.; Reuvers, A. J.; Boom, R. M.; Wienk, I. M. Microstructures in phase-inversion membranes. Part 1. Formation of macrovoids. J. Macromol. Sci. 1992, 73, 259-275.

(28) Xi, J.; Li, Z.; Yu, L.; Yin, B.; Wang, L.; Liu, L.; Qiu, X.; Chen, L. Effect of degree of sulfonation and casting solvent on sulfonated poly(ether ether ketone) membrane for vanadium redox flow battery. J. Power Sources 2015, 285, 195-204.

(29) Liu, B.; Hu, W.; Robertson, G. P.; Guiver, M. D. Poly(aryl ether ketone)s with carboxylic acid groups: synthesis, sulfonation and crosslinking. J. Mater. Chem. 2008, 18, 4675.

(30) Rhee, C. H.; Kim, Y.; Lee, J. S.; Kim, H. K.; Chang, H. Nanocomposite membranes of surface-sulfonated titanate and Nafion for direct methanol fuel cells. J. Power Sources 2006, 159, 1015-1024.

(31) Ratner, M. A.; Shriver, D. F. Ion Transport in Solvent-Free Polymers. Chem. Rev. 1988, 88, 109-124.

(32) Armand, M. The history of polymer electrolytes. Solid State Ionics 1994, 69, 309-319.

(33) $\mathrm{Xu}, \mathrm{K}$. Electrolytes and interphases in Li-ion batteries and beyond. Chem. Rev. 2014, 114, 11503-11618.

(34) $\mathrm{Xu}, \mathrm{K}$. Nonaqueous Liquid Electrolytes for Lithium-Based Rechargeable Batteries. Chem. Rev. 2004, 104, 4303-4418.

(35) Zhu, Y.-H.; Yang, X.; Bao, D.; Bie, X.-F.; Sun, T.; Wang, S.; Jiang, Y.-S.; Zhang, X.-B.; Yan, J.-M.; Jiang, Q. High-Energy-Density Flexible Potassium-Ion Battery Based on Patterned Electrodes. Joule 2018, 2, 736-746.

(36) Meng, F.; Zhong, H.; Yan, J.; Zhang, X. Iron-chelated hydrogelderived bifunctional oxygen electrocatalyst for high-performance rechargeable Zn-air batteries. Nano Res. 2017, 10, 4436-4447.

(37) Wang, H.-G.; Yuan, S.; Ma, D.-L.; Zhang, X.-B.; Yan, J.-M. Electrospun materials for lithium and sodium rechargeable batteries: from structure evolution to electrochemical performance. Energy Environ. Sci. 2015, 8, 1660-1681.

(38) Liu, T.; Liu, Q.-C.; Xu, J.-J.; Zhang, X.-B. Cable-Type WaterSurvivable Flexible Li-O2Battery. Small 2016, 12, 3101-3105.

(39) Komaba, S.; Hasegawa, T.; Dahbi, M.; Kubota, K. Potassium intercalation into graphite to realize high-voltage/high-power potassium-ion batteries and potassium-ion capacitors. Electrochem. Commun. 2015, 60, 172-175.

(40) Eftekhari, A.; Jian, Z.; Ji, X. Potassium Secondary Batteries. ACS Appl. Mater. Interfaces 2016, 9, 4404-4419.

(41) Kundu, D.; Adams, B. D.; Duffort, V.; Vajargah, S. H.; Nazar, L. F. A high-capacity and long-life aqueous rechargeable zinc battery using a metal oxide intercalation cathode. Nat. Energy 2016, 1, 16119.
(42) Brissot, C.; Rosso, M.; Chazalviel, J.-N.; Lascaud, S. Dendritic growth mechanisms in lithium/polymer cells. J. Power Sources 1999, $81-82,925-929$.

(43) Evans, J.; Vincent, C. A.; Bruce, P. G. Electrochemical measurement of transference numbers in polymer electrolytes. Polymer 1987, 28, 2324.

(44) Seh, Z. W.; Sun, J.; Sun, Y.; Cui, Y. A Highly Reversible RoomTemperature Sodium Metal Anode. ACS Cent. Sci. 2015, 1, 449-455.

(45) Bieker, G.; Winter, M.; Bieker, P. Electrochemical in situ investigations of SEI and dendrite formation on the lithium metal anode. Phys. Chem. Chem. Phys. 2015, 17, 8670-8679.

(46) Song, J.; Xiao, B.; Lin, Y.; Xu, K.; Li, X. Interphases in SodiumIon Batteries. Adv. Energy Mater. 2018, 8, 1703082.

(47) Chen, Y.; Schneider, P.; Erbe, A. Investigation of native oxide growth on zinc in different atmospheres by spectroscopic ellipsometry. Phys. Status Solidi A 2012, 209, 846-853.

(48) Kundu, D.; Black, R.; Berg, E. J.; Nazar, L. F. A highly active nanostructured metallic oxide cathode for aprotic $\mathrm{Li}-\mathrm{O}_{2}$ batteries. Energy Environ. Sci. 2015, 8, 1292-1298.

(49) Suo, L.; Borodin, O.; Gao, T.; Olguin, M.; Ho, J.; Fan, X.; Luo, C.; Wang, C.; Xu, K. "Water-in-salt" electrolyte enables high-voltage aqueous lithium-ion chemistries. Science 2015, 350, 938-943.

(50) Landers, J.; Gor, G. Y.; Neimark, A. V. Density functional theory methods for characterization of porous materials. Colloids Surf., A 2013, 437, 3-32.

(51) Jiang, X.; Zeng, Z.; Xiao, L.; Ai, X.; Yang, H.; Cao, Y. An AllPhosphate and Zero-Strain Sodium-Ion Battery Based on $\mathrm{Na}_{3} \mathrm{~V}_{2}\left(\mathrm{PO}_{4}\right)_{3}$ Cathode, $\mathrm{NaTi}_{2}\left(\mathrm{PO}_{4}\right)_{3}$ Anode, and Trimethyl Phosphate Electrolyte with Intrinsic Safety and Long Lifespan. ACS Appl. Mater. Interfaces 2017, 9, 43733-43738. 